\title{
Why so many Agta boys? Explaining 'extreme' sex ratios in Philippine foragers
}

\author{
Abigail E. Page ${ }^{1,2 *}$, Sarah Myers ${ }^{1 \ddagger}$, Mark Dyble $^{3}$ and Andrea Bamberg Migliano ${ }^{1,4}$ \\ ${ }^{1}$ Department of Anthropology, University College London, London, UK, ${ }^{2}$ Department of Population Health, London School \\ of Hygiene and Tropical Medicine, London, UK, ${ }^{3}$ Jesus College, University of Cambridge, Cambridge, UK and ${ }^{4}$ Department \\ of Anthropology, University of Zurich, Zurich, Switzerland \\ ${ }^{\star}$ Corresponding author. London School of Hygiene \& Tropical Medicine Keppel Street London WC1E 7HT. E-mail: abigail. \\ page@lshtm.ac.uk
}

\begin{abstract}
Male-biased sex ratios have been observed in multiple small-scale societies. Although intentional and systematic female-biased mortality has been posited as an explanation, there is often a lack of ethnographic evidence of systematic female neglect and/or infanticide. The Agta, a foraging population from the Philippines, have a skewed sex ratio of 1.29 (129 males per 100 females) aged 15 years or under. We hypothesised that this skew was not caused by greater female deaths, but due to an adaptive response, where more males were produced at birth in reaction to high male-biased extrinsic mortality. To test this hypothesis we utilise census, childcare and mortality data from 915 Agta. The Agta's sex ratio is significantly male-biased in the $<1(n=48,2: 1)$ and $1-5$ year $(n=170,1.39: 1)$ age cohorts; however, we find no evidence of systematic female neglect in patterns of childcare. Furthermore, the sex ratio decreases over cohorts, becoming balanced by the end of the juvenile period, owing to significantly higher male mortality. Taken together, these results are not supportive of female infanticide or neglect, and instead suggest an adaptive mechanism, acting in utero as a response to male-biased juvenile mortality, following Fisherian principles of equalising parental investment.
\end{abstract}

Keywords: Biased sex ratios; female-biased infanticide/neglect; male-biased mortality; hunter-gatherers; Agta

\section{Introduction}

Many species of sexually reproducing organisms have biased sex ratios, including mammals, birds, frogs and lizards (Navara 2013; West et al. 2002), varying both at the species and at the population level. Humans are no exception; worldwide, more boys than girls are born, with the sex ratio at birth in 2016 standing at 1.07 (United Nations 2017). Yet cross-cultural variation exists, with African countries tending towards lower sex ratios (Mace and Jordan 2005) - of the 50 counties for which data is compiled, the sex ratio at birth in 2017 ranged from 1.01 to 1.06 , with the majority $(n=26)$ at 1.02 (CIA 2018). Much of the literature on highly skewed sex ratios in human populations cites infanticide or neglect of one sex, usually females, as the causal explanation (Hesketh and Xing 2006). Although such explanations are undoubtedly valid in certain contexts, the fact that sex ratios vary in other species without necessitating sex-biased infanticide and/or neglect suggests that the mechanisms in human populations need not be exclusively behavioural. Furthermore, the non-human literature also indicates an evolutionary or functional rationale for sex ratio manipulation which should also apply to humans; previous tests, largely in WEIRD (Western, educated, industrialised, rich and democratic) populations replete with potential confounds (Beckerman et al. 2017), however,

\$These authors contributed equally to the paper.

( $)$ The Author(s) 2019. This is an Open Access article, distributed under the terms of the Creative Commons Attribution licence (http://creative commons.org/licenses/by/4.0/), which permits unrestricted re-use, distribution, and reproduction in any medium, provided the original work is properly cited. 
have found mixed support for this (Cronk 2007; Lazarus 2002). Here we set out to explore the underlying explanation - in terms of both evolutionary function and potential mechanism - for the malebiased sex ratio in the Palanan Agta, a foraging population from the Philippines.

Fisher (1930) proposed that because, in sexually reproducing species, every individual has one parent of either sex, within a population parents should invest equally in sons and daughters. Thus, when the costs of raising sons and daughters are equal, in a population with a biased sex ratio the parents of the rarer sex will have a selective advantage, driving the sex ratio back to a balanced state, producing an evolutionarily stable strategy of a 1:1 sex ratio. However, when the relative costs of the sexes are unequal, parental investment across the sexes is equalised when females produce more of the cheaper sex (McElreath and Boyd 2007). Where the mortality of one sex is consistently higher than the other before the end of parental investment, the higher-mortality sex will not receive their full share of investment (Fisher 1930). For every 100 of the higher-mortality sex successfully reared, the total investment is the sum of the investment in those surviving to independence and that in those who died prematurely. Consequently, the average cost of each of this sex reared to independence is greater, but less for each one born, than it is for members of the opposite sex at the corresponding stages. By adjusting the sex ratio at birth in favour of the higher-mortality sex, parents can equalise their investment (Clutton-Brock et al. 1982; Fisher 1930; Skogland 1986). Additionally, where the competition or cooperation between kin differs by sex, the cost-benefit ratio of producing one sex over another is also expected to vary. Parents are thus expected to increase the number of the most 'helpful' sex, and thus, optimise their inclusive fitness (Hamilton 1967; Silk 1983). Finally, offspring sex ratios may also be adjusted depending on the condition of the mother (Trivers and Willard 1973). Mechanisms enabling sex ratio variation are predicted to be selected for when the benefits to parental fitness of this behaviour outweigh the costs (West et al. 2002), and the activation of such mechanisms is expected to be context dependent (Sieff et al. 1990).

Early ethnographers documenting hunter-gatherers, particularly those working in the Arctic, published accounts of extensive sex-selective infanticide resulting in high (male-biased) sex ratios (Rasmussen 1931; Weyer 1932). For instance, the juvenile (under 16 years) sex ratios of 10 Inuit populations from 1880 to 1930 ranged from 1.05 to 2.24 (Smith and Smith 1994). Subsequently, male-skewed juvenile sex ratios have been widely documented in foragers (Table 1).

These sex ratios are often seen as 'extreme' and, as such, taken as evidence of infanticide and/or systematic female neglect (Hewlett 1991; Hewlett et al. 2000; Hurtado and Hill 1987; Sharp 1940; Smith and Smith 1994), implying that it is possible to establish infanticide from sex ratios alone (Kelly 2013). However, while female-biased infanticide and neglect have been documented in larger-scale societies (United Nations 2017; Reza et al. 2001; Watts and Zimmerman 2002), and some non-egalitarian foragers [Inuit populations from the northern Arctic (Balikci 1970; Irwin 1989; Rasmussen 1931; Weyer 1932); the Aché of eastern Paraguay (Hill and Hurtado 1996; Hill and Kaplan 1988); some Australian Aboriginal groups (Rose 1960; Sharp 1940); and the Cuiva of Venezuela (Hurtado and Hill 1987)], they remain ethnographically rare in egalitarian foragers. Amongst the Agta hunter-gatherers from the Philippines, sex-biased infanticide has never been witnessed, by our group or others (Headland 1989; Minter 2018 personal communication). Such an explanation is also at odds with the egalitarian social and political structure of many immediate-return foraging populations (Dyble et al. 2015; Kelly 2013). Indeed, ethnographers, in a range of foraging populations worldwide, frequently find no sex bias in investment by parents or a stated preference between the sexes (Eder 1987; Gardner 1988; Hewlett 1993; Morris 1982; Turnball 1961; Yengoyan 1970).

In attempting to explain male-biased sex ratios in foragers, evolutionary anthropologists have typically explored the functional question of 'why are males preferred to females?', arguing that more sons increase the relative fitness of their kin as males have higher mean calorific productivity (Hewlett 1991; Hewlett et al. 2000; Hill and Hurtado 1996; Smith and Smith 1994). While calorific contributions are an indicator of cooperation, we cannot quantify a measure of cooperativeness by only exploring maledominated food production. For instance, cooperation in breeding is extensive in foragers (Crittenden and Marlowe 2008; Kramer 2010; Meehan 2005) and unmarried female siblings frequently help raise 
Table 1. The juvenile sex ratios and the sample sizes on which they are based as reported by Hewlett (1991) and Headland $(1989)^{\mathrm{b}}$ - the Palanan Agta data are our own. ${ }^{\mathrm{c}}$ Apparently male-biased sex ratios are in bold

\begin{tabular}{|c|c|c|c|c|c|}
\hline \multirow[b]{2}{*}{ Population } & \multicolumn{2}{|c|}{ Juvenile sex ratio } & \multirow[b]{2}{*}{ Population } & \multicolumn{2}{|c|}{ Juvenile sex ratio } \\
\hline & $\# \mathrm{~m} / \# f$ & Ratio & & $\# \mathrm{~m} / \# \mathrm{f}$ & Ratio \\
\hline Ache $^{a}$ & $55 / 36$ & 1.53 & Agta (Casiguran 1977) & $124 / 102$ & 1.22 \\
\hline Agta (Casiguran 1984) & $125 / 86$ & 1.45 & Agta (Palanan) ${ }^{c}$ & $281 / 217$ & 1.29 \\
\hline $\mathrm{Aka}^{\mathrm{a}}$ & $160 / 139$ & 1.15 & Batak $^{a}$ & $77 / 72$ & 1.07 \\
\hline Batek $^{a}$ & $31 / 18$ & 1.72 & Bihor $^{a}$ & $30 / 18$ & 1.67 \\
\hline Chenchu $^{a}$ & $182 / 195$ & 0.93 & Central !Kung $^{\mathrm{a}}$ & $49 / 43$ & 1.14 \\
\hline $\mathrm{Efe}^{\mathrm{a}}$ & $67 / 63$ & 1.06 & Groot Eylandt $^{a}$ & $46 / 36$ & 1.28 \\
\hline Hill Pandaram $^{a}$ & $142 / 133$ & 1.07 & Inuit $^{a}$ & $64 / 57$ & 1.12 \\
\hline Mbuti $^{\mathrm{a}}$ & $101 / 84$ & 1.19 & Northern !Kung ${ }^{a}$ & $64 / 79$ & 0.81 \\
\hline Ongee $^{a}$ & $9 / 15$ & 0.60 & Paliyan $^{a}$ & $9 / 13$ & 0.69 \\
\hline Siriono ${ }^{a}$ & $28 / 32$ & 0.87 & Xavante $^{a}$ & $172 / 139$ & 1.24 \\
\hline
\end{tabular}

their siblings more than unmarried males, as is in the case in the Palanan Agta (Page 2016). Thus, we might equally expect parents to prefer females (Emlen et al. 1986; Mace and Jordan 2005). Furthermore, cooperation is not confined to caloric contribution and allocare but extends across a number of domains which are substantially harder to quantify. It is incredibly complex to measure and reliably compare contributions to parental inclusive fitness of the sexes, as in part it will depend on one's operationalisation of 'help'.

The relative aid provided by the sexes is not necessarily the only reason sons and daughters differ; as noted, sex-biased extrinsic mortality (i.e. mortality beyond parental control) alters the relative costs of the sexes (Fisher 1930). In many avian and mammalian species, males are frequently the less viable sex (Clutton-Brock and Iason 1986; Promislow 1992) and male-biased sex ratios at birth have been argued to be the result of an optimal strategy when males are vulnerable to mortality before the end of parental investment (Austad and Fischer 2016; Clutton-Brock et al. 1982; Skogland 1986). A trend for male-biased mortality extends to humans, even in low-mortality contexts (Drevenstedt et al. 2008; Wells 2000). This has been suggested to underlie the common human at-birth sex ratio of 1.05-1.07 (Mace and Jordan 2005), indicating the existence of biological sex ratio manipulation mechanisms in humans. Arguably then, the high juvenile sex ratio in many hunter-gatherers may be the product of a facultative alteration, amplified by higher mortality risks (Gurven and Kaplan 2007; Hill et al. 2007). One need not default to a behavioural explanation of infanticide/neglect when sex ratios seem 'extreme'.

The hunter-gatherer literature has largely overlooked biological mechanisms, proceeding on the assumption that the sex ratio at birth is fixed and parents must augment their fitness after sex has been determined (Maynard Smith 1980). However, post-birth infanticide and selective neglect are energetically inefficient compared with a biological mechanism capable of altering the primary (at conception) or secondary (at-birth) sex ratio. Therefore, it is reasonable to suggest there would have been a selective advantage in the human lineage of both being able to regulate the optimal sex to bear in a given environment and in terminating investment prior to birth, as suggested more broadly by West et al. (2002). This is certainly the case in other taxa; birds, for instance, have been found to show sex-selective re-absorption of eggs after conception (Komdeur et al. 1997). In mammals, biased prenatal mortality owing to maternal nutritional (Labov et al. 1986; McClure 1981) and social stress (Silk 1983) and increased hormone levels at the time of conception (James 1986) have all been associated with at-birth sex ratio skews. In humans, the use of medical records from the 2011 Japanese earthquake and tsunami - which dramatically increased extrinsic mortality risks 
- indicate the existence of a biological mechanism(s) which both reduced implantation rates of male zygotes and triggered miscarriages of male foetuses later in gestation (Catalano et al. 2013).

Foraging populations are often small, and what may appear to be an 'extreme' sex ratio may be an artefact of the limited number of observations. Therefore, it is first essential to demonstrate that sex ratios are in fact statistically male-biased. Here, we do so utilising census and reproductive histories. We detail at-birth, infant and juvenile sex ratios in the Palanan Agta. We hypothesise that female neglect and/or infanticide are not the mechanisms underlying the Agta's high sex ratio. Instead, we argue that these trends may originate from an adaptive adjustment of the sex ratio at birth in response to male-biased extrinsic mortality during childhood and adolescence. From this hypothesis, we test three predictions. In Prediction 1, firstly, we explore the sex ratios across age cohorts using proportion tests to assess the prediction that sex ratios decrease over childhood, rather than becoming increasingly male-biased as expected when mortality is female-biased (illustrated by plotting five differing mortality regimes). In Prediction 2, secondly, we look at parental care data relating to 35 children to test the prediction that there is no evidence of systematic female neglect. In Prediction 3, finally, we conduct proportion tests and hazard analysis on childhood mortality data to test the prediction that mortality prior to the end of parental investment is male, not female, biased.

\section{Methods}

Data collection occurred over two field seasons from April to June 2013 and February to October 2014. We visited 20 Agta camps two to three times to collect both demographic and childcare data; during this time we met 915 Agta. No formal sampling techniques were used; as this was a small population, we were able to census and interview the majority of the population. This research and fieldwork was approved by UCL Ethics Committee (UCL Ethics code 3086/003) and carried out with permission from local government and tribal leaders in Palanan. Informed consent was obtained from all participants, and parents signed the informed consents for their children (after group and individual consultation and explanation of the research objectives in the indigenous language).

\section{The Agta}

The Agta reside in the Northern Sierra Madre Natural Park in the northeast of Luzon, a protected area that consists of a mountainous tropical rainforest and includes the coastal beaches, coral reefs and marine eco-system of the Pacific Ocean. Mobility both within Palanan and between Palanan and neighbouring areas makes it difficult to calculate the exact population of Agta in Palanan at any one time, although Minter (2010) estimated a population of 1000. The Agta rely heavily on foraging modes of subsistence (76.5\% of out-of-camp economic activity) vs non-foraging activities (23.5\%), but this varies by camp and location (Page et al. 2016). Riverine and marine spearfishing provides the primary source of animal protein, supplemented by inter-tidal foraging and hunting and the gathering of wild foods, as well as low-intensity cultivation (Dyble et al. 2016; Minter 2010; Page et al. 2016). The Agta have also long resided with neighbouring farming populations, trading meat for rice and, historically, tubers (Peterson 1978). The Agta practise serial monogamy and have a total fertility rate of 7.7 (Page et al. 2016). Infant and childhood mortality rates are also high, with $38.9 \%$ of offspring reported to have been born dying before the age of 16 years (Page et al. 2016); 19\% of children died before reaching 1 year old (reaching 36.9\% if stillbirths and miscarriages are included), while $13.9 \%$ died between ages 1 and 5 years, and 6\% died aged 5-15 years.

\section{Reproductive histories and juvenile mortality data}

We (A.E.P. and M.D.) interviewed and collected reproductive histories from all adult women encountered $(n=161)$, producing a record of all reported living $(n=632)$ and deceased $(n=210)$ children. Underreporting of infant mortality is always a possibility as mothers may be unwilling to report a 
child who later died (Ellison et al. 2000). To limit the issue of underreporting, we asked mothers to report all children born, including miscarriages or stillbirths, in the order they were born and their birth interval. If there was a large interbirth interval between any two children we would enquire if there was a specific reason, which often prompted a mother to report a deceased child. Furthermore, genealogical interviews were conducted with all adult members of the communities, therefore missing children would become evident when, for instance, a wife's and husband's reports did not match, or did not match that of any other reliable close kin member (generally a co-residing sister or mother). In this case we would go back and check with mother to resolve the issue. There is some evidence of older women underreporting births and, by extension, deaths, as evident in differences in the completed fertility rate of mothers who had recently finished their reproductive lifespan (aged $40-55, n=31,8.5$ reported children ever born) compared with older mothers $(n=12,6.5$ reported children ever born). Nonetheless, our mortality figures fall into line with previous research findings among immediate-return foragers (Kelly 2013).

If a child was reported to have died, we enquired about the cause of death and their approximate age at death. Cause of death was documented for 155 deceased children aged 15 years or under at time of death. Deaths were classified as either disease-related $(n=123)$ - including malaria, hepatitis, respiratory trait infections, gastro-intestinal disease, measles and malnutrition - or non-disease causes $(n=32)$ - including accidents, violence and environmental events such as typhoons. Ages were established for the entire population using relative age lists and a Bayesian methodology which accounts of the inherent uncertainty in aging a hunter-gatherer population with no concept of calendar years (see Diekmann et al. 2017 for full details). Estimated survival times were calculated for 623 children for whom sex and date of birth and, where applicable, date of death were available and whose mothers were interviewed on multiple camp visits (increasing data validity).

While in the field we also documented a number of 'witnessed' births $(n=16)$. These births do not reflect all births which occurred during 2013-2014, as some women gave birth before we arrived and others were yet to give birth when fieldwork ended and we did not know of all pregnancies, thus we cannot put too much weight on analysing this cohort. Nonetheless, it is important to include it as it is our only measure of a 'true' at-birth sex ratio, as opposed to an at-birth sex ratio calculated from reported births, and also speaks directly to the question of sex-biased infanticide.

\section{Parental investment observations}

Focal follows were conducted on 35 children [17 infants aged $0-1.9$ years (average $0.87 \pm 0.55$ ) and 18 toddlers aged 2-5.9 years (average $3.9 \pm 1.2$ )] for $9 \mathrm{~h}$ per child to assess parental investment. These intensive observations were conducted using focal sampling techniques detailed by Meehan (2005) and further details and descriptive statistics can be found in the Supporting Information (see Table S1). The following parental activities were documented and classified into either 'high' or 'low' investment: high - carrying, feeding, grooming, medical attention, teaching, playing; low - talking to, watching, being in proximity. For the 35 children $(13=$ female $)$ observed this produced 124,701 dyadic child-carer data points, of which 24,949 were between mothers $(n=23)$ or fathers $(n=22)$.

\section{Analysis}

\section{Describing sex ratios in the Agta}

We plot census sex ratios across age cohorts and assess whether: (1) the apparent male bias across juvenile age cohorts (in the $<1,1-5,6-15$ and 16-25 year olds) is significantly different from 1:1 using two-tailed binomial exact tests; and (2) the male bias in the 'witnessed' births and the $<1$ cohort is greater than what demographers consider to be the 'normal' sex ratio of 1.05-1.07 (Hesketh and Xing 2006) using one-tailed binomial exact tests. We report the 95\% confidence intervals (CI) or lower-bound CI (LCI) for one-tailed tests; for full results see Table S2. We also present the sex ratios 
of individual mothers who had two or more children, in acknowledgement that population-level analyses may mask individual variation (West et al. 2002), and the sex ratio of yearly births cohorts.

\section{Prediction 1 - sex ratios become decreasingly male biased}

Proportion tests using census data. To test Prediction 1, we assessed the changes in the sex ratio over the period of parental investment, considered to end during the 16-25 year old cohort based on the average age at marriage being 19 for females and 22 for males (Minter 2010; Smith and Smith 1994). We performed Pearson chi-squared $\left(\chi^{2}\right)$ tests to assess whether the proportion of males differed significantly between cohorts, assessing differences in distribution for all combinations of the following cohort groupings: $<1,1-5,6-15$ and $16-25$ year old cohorts.

Illustrating differential mortality patterns on sex ratios trends. Different patterns of mortality between the sexes should leave a unique signature, traceable in the relative distribution of the sexes across age cohorts of a population. By creating hypothetical data for five different demographic scenarios we illustrate how sex ratios respond to different mechanisms known to influence sex ratios. Comparing these patterns with that seen in our census data, we seek to gauge the plausible mechanism underlying the sex ratios observed in the Agta. Five sex ratio distributions were created by subjecting 1000 hypothetical, simultaneous births to five demographic scenarios over 15 population years [mirroring the cut-off commonly used for differentiating juvenile and adult mortality in small-scale societies (Hewlett 1991; Kelly 2013)].

This exercise is intended to be purely illustrative, highlighting the alternative trajectories of sex ratios as a result of differential juvenile mortality by sex and, as such, the specific sex ratios employed are irrelevant; however, the statistics (Table 2, SI methods) chosen for each mortality regime are within the bounds of those documented in 'real-world' forager populations (Blurton Jones 2016; Kelly 2013). For the sake of this illustration we make the simplifying assumption that, where purely behavioural mechanisms underlie sex ratio patterns, the sex ratio at birth will be balanced.

\section{Prediction 2 - females do not receive less parental investment}

Multilevel analysis of observational childcare data. To test the prediction that females do not receive differential levels of care we used the focal follow data to create three investment measures: (a) highinvestment interactions; (b) low-investment interactions; (c) total interactions (sum of high and low) for each child-parent dyad. Mothers and fathers were assessed both in combination and separately, giving three sources of investment: (a) parental investment; (b) maternal investment; and (c) paternal investment. There was slight variability in the total duration of observations; to standardise this, the data were transformed into a proportion of the total number of observations, theoretically ranging between 0 (no interaction) and 1 (constant interaction). For a breakdown of the average proportion of investment by type and source see Table S1. The proportion of interactions acted as the outcome variable and child sex was the predictor variable (reference = male). Multilevel models (using the $\mathrm{R}$ package Ime4) were used to capture the non-independence of data points as children were clustered into households. When 'paternal high-investment interactions' were the outcome variable, the household variance was reduced to 0 , indicating that the multilevel structure was not parsimonious; in this instance, parental investment was assessed using a single-level multivariable regression. Given the small sample size, the models were kept as simple as possible owing to power considerations. Therefore, each model contained a term for child sex and the child's age.

Wilcoxon rank sum tests within families. While the sample is small, we explored whether brothers and sisters received differential investment (sibling sets $n=5$, children $n=12$ ) using Wilcoxon rank sum tests. This additional analysis was to examine whether parents invested more in sons compared with daughters when they had a daughter, as arguably parents with only sons or only daughters may not show differential investment patterns. 


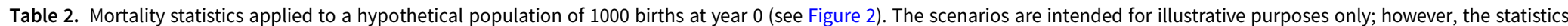

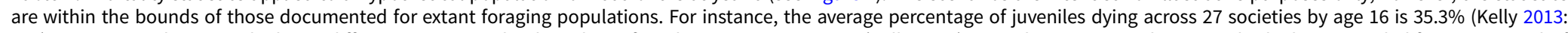

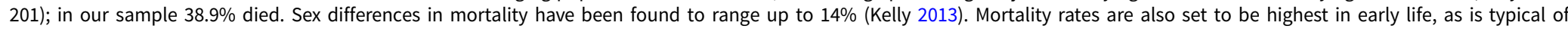

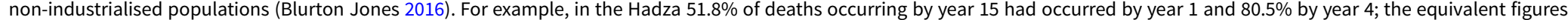
for the Agta are $48.8 \%$ and $84.5 \%$ (Page et al. 2016). At birth sex ratios have been previously documented as being as high as 122 (Hewlett 1991 ).

\begin{tabular}{|c|c|c|c|c|c|c|}
\hline \multirow[b]{2}{*}{ Scenario } & \multirow[b]{2}{*}{$\begin{array}{c}\text { Overall juvenile } \\
\text { mortality by } \\
\text { year } 15(\%)\end{array}$} & \multirow[b]{2}{*}{$\begin{array}{l}\text { Sex } \\
\text { ratio at } \\
\text { birth }\end{array}$} & \multicolumn{3}{|c|}{ Differential mortality by sex } & \multirow[b]{2}{*}{ Rationale behind the statistics } \\
\hline & & & $\begin{array}{l}\text { Percentage of } \\
\text { overall mortality } \\
\text { by year } 1(\mathrm{~m} / \mathrm{f})\end{array}$ & $\begin{array}{l}\text { Percentage of } \\
\text { overall mortality } \\
\text { by year } 4(\mathrm{M} / \mathrm{F})\end{array}$ & $\begin{array}{l}\text { Percentage of } \\
\text { overall mortality } \\
\text { by year } 15(\mathrm{~m} / \mathrm{f})\end{array}$ & \\
\hline \multicolumn{7}{|l|}{$\begin{array}{l}\text { Mechanism - } \\
\text { none }\end{array}$} \\
\hline $\begin{array}{l}\text { 1. Higher male } \\
\text { mortality }\end{array}$ & 36 & 100 & $50 / 50$ & $75 / 75$ & $41 / 31$ & $\begin{array}{l}\text { 'Naturally' higher male mortality, no } \\
\text { compensatory mechanisms = baseline } \\
\text { condition }\end{array}$ \\
\hline \multicolumn{7}{|l|}{$\begin{array}{l}\text { Mechanism - } \\
\text { behavioural }\end{array}$} \\
\hline $\begin{array}{l}\text { 2. Female } \\
\text { infanticide } \\
\text { and neglect }\end{array}$ & 41 & 100 & $50 / 65$ & $75 / 75$ & $36 / 46$ & $\begin{array}{l}\text { Compared with baseline - males } \\
\text { preferentially treated, so more survive; a } \\
\text { lot more females die owing to neglect, } \\
\text { with majority of excess deaths in the first } \\
\text { year }\end{array}$ \\
\hline $\begin{array}{l}\text { 3. Female } \\
\text { infanticide } \\
\text { only }\end{array}$ & 43 & 100 & $50 / 65$ & $75 / 90$ & $41 / 46$ & $\begin{array}{l}\text { Compared with baseline - females } \\
\text { experience excess death in first year, } \\
\text { male mortality unaffected }\end{array}$ \\
\hline $\begin{array}{l}\text { 4. Female } \\
\text { neglect }\end{array}$ & 41 & 100 & $50 / 50$ & $75 / 75$ & $36 / 46$ & $\begin{array}{l}\text { Compared with baseline - males } \\
\text { preferentially treated, so more survive; a } \\
\text { lot more females die owing to neglect }\end{array}$ \\
\hline \multicolumn{7}{|l|}{$\begin{array}{l}\text { Mechanism - } \\
\text { biological }\end{array}$} \\
\hline $\begin{array}{l}\text { 5. Male biased } \\
\text { at birth }\end{array}$ & 36 & 120 & $41 / 31$ & $50 / 50$ & $75 / 75$ & $\begin{array}{l}\text { Compared with baseline - more males born, } \\
\text { otherwise the same }\end{array}$ \\
\hline
\end{tabular}


Prediction 3 - mortality is male, not female, biased

Proportion tests on cause of deaths and gender bias in stillbirths. To test the prediction that mortality is male-biased we first assessed sex-dependent trends in cause of death in a subset of the sample $(n=$ 155 ) for which we had accurate reporting of cause of death. A two-way Pearson $\chi^{2}$ test was performed to assess whether the distribution of cause of death differed by sex; owing to sample size considerations this test was performed on the juvenile cohort as a whole. If infanticide is an important mechanism underlying skewed sex ratios, yet a population is unwilling to disclose such behaviour, more females may simply be reported as stillborn. Therefore, an exact binomial test was also performed to assess whether the proportion of stillbirths $(n=20)$ differed by sex.

Hazard analysis on juvenile mortality. Finally, a hazard analysis was performed to assess whether the proportional hazard of death across the juvenile period differed by sex. A multilevel Cox regression model was run (using the $\mathrm{R}$ package survival), in which all offspring of known sex $(n=623$; miscarriages were excluded but stillborns included as sex was reported) were entered into the model and their survival duration in months assessed - for offspring who were alive at the time of data collection, data was right censored at either their current age or at 192 months (i.e. 16 years) to indicate the end of parental investment. Offspring $(n=623)$ were clustered by mother $(n=126)$ and camp $(n$ $=12$ ), resulting in a population-averaged model. Model selection based on Akaike's information criterion score was conducted to assess whether including year of the offspring's birth (to control for temporal effects (Ross et al. 2016), offspring's birth order (associated with mortality risk in other populations (Gellatly and Petrie 2017; Ross et al. 2016; Uggla and Mace 2016), or both caused less information to be lost - the model presented reflects the best fit, for other versions see the Supporting Information. Data processing, analysis and plotting were conducted in $\mathrm{R}$ version 3.1.2 (R Core Team 2012).

\section{Results}

\section{Describing sex ratios in the Agta}

The sex ratios by age cohorts from 2013-2014 are presented in Figure 1; the sex ratio is significantly different from $1: 1$ in the $<1$ and $1-5$ year cohorts, after which the sex ratio remains largely balanced in reproductively aged cohorts. The overall skew of the $<16 \mathrm{~s}$ was significantly male biased at $1.29[n=281: 217$, males $=0.564,95 \%$ CI $(0.520,0.607)]$. The sex ratio was greater than 1.07 (proportion $=0.517)$ in the $<1 \mathrm{~s} \quad(n=32: 16$, males $=0.67, \mathrm{LCI}=0.539$ one-tailed). Furthermore, while a small sample, in the 16 births that occurred during fieldwork there was a male bias of 3.00 , significantly exceeding 1.06 ( $n=12: 4$, males $=0.75$, LCI $=0.516$ one-tailed $)$, without any occurrence of female-biased infanticide. Full proportion test results can be seen in Table S2.

Using reproductive histories, there was a trend for individual mothers to give birth to more boys than girls; of mothers who had given birth to at least 2 infants, 75 women had male-biased sex ratios, 22 balanced and 43 female-biased (Figure 2a). This relationship appears uninfluenced by maternal age, suggesting a lack of temporal trends, including under-reporting by older mothers. Older mothers, who on average had more children, also did not appear to have more balanced ratios (the sex ratio plotted against number of births, irrespective of age, can be seen in Figure S1).

There is also a trend for yearly birth cohorts to be male biased, at least since 1990 (1.22, Figure 2b): 15 male-biased, 3 balanced, 7 female-biased. Birth cohorts were more likely to be malebiased in more recent years, when sample sizes are also larger and closer to capturing the total number of births in a year. Figure $2 \mathrm{~b}$ also highlights the issue of sample sizes diminishing over time when assessing yearly birth cohort sex ratios retrospectively. Nevertheless, based on both census and retrospective data there is clear reason to consider the Palanan Agta sex ratio to be malebiased in the early juvenile period. 


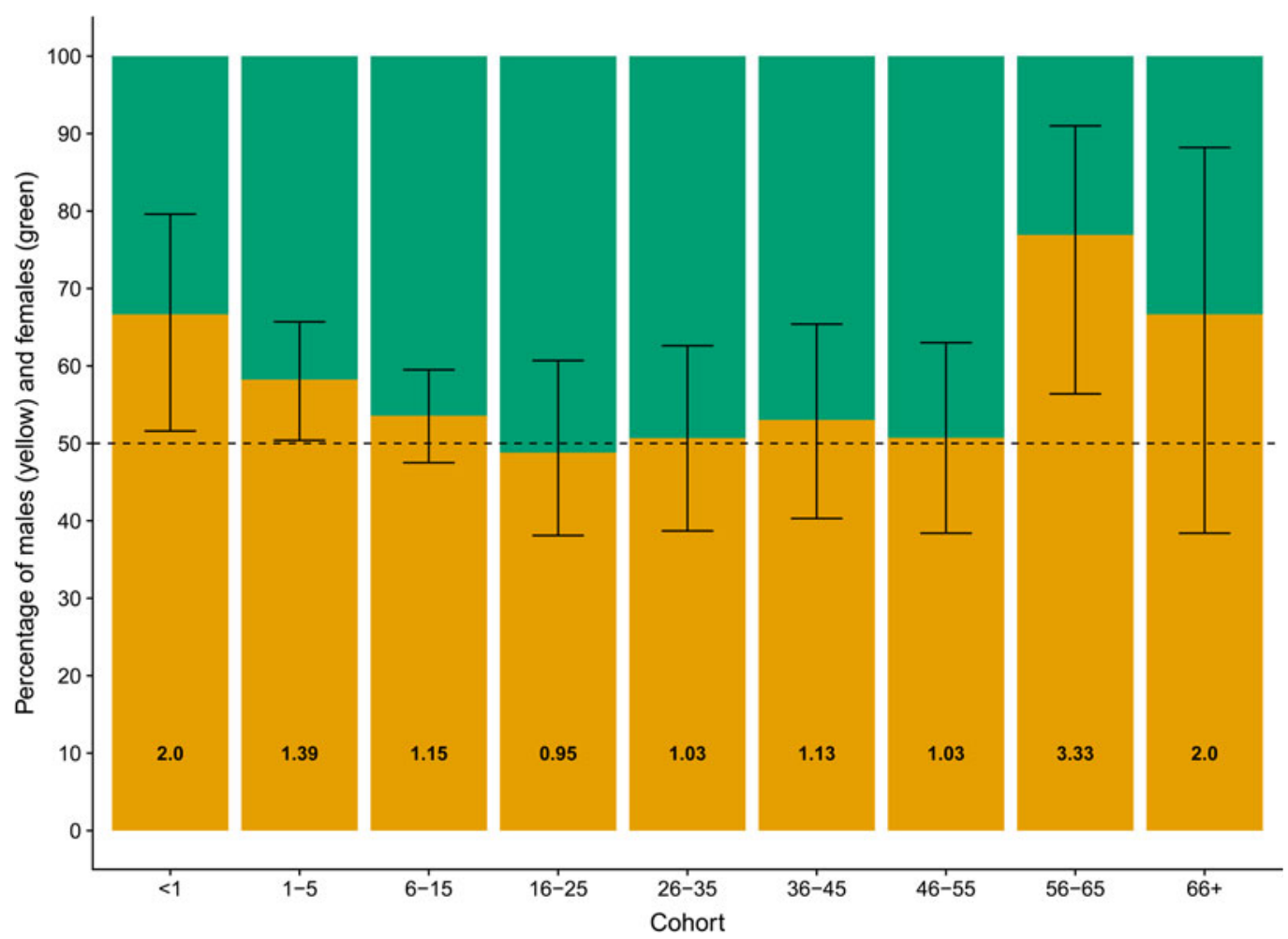

Figure 1. The percentage distribution of Agta males and females across age cohorts. Yellow (bottom) portion of the bars represents males; the green (top) portion represents female. The hashed line represents a balanced sex ratio and the numbers at the bottom of the bars are the sex ratios of each age group. Error bars are $95 \%$ confidence intervals of the observed proportions based on two-tailed binomial proportion tests. Sample sizes are as follows: $<1, n=48 ; 1-5, n=170 ; 6-15, n=280 ; 16-25, n=168 ; 26$ $35, n=73 ; 36-45, n=66 ; 46-55, n=69 ; 56-66, n=26$; and 66+, $n=15$.

\section{Prediction 1 - sex ratios become decreasingly male biased}

\section{Hypothesis tests using census data}

Pearson $\chi^{2}$ tests find the proportion of males to be significantly higher in the $<1$ year cohort $(0.667)$ compared with the 16-25 years cohort $(0.488)$ [Pearson $\chi^{2}$ (d.f. $\left.=1, n=216\right)=4.777, p=0.029$ ], supporting the hypothesus that a reduction in sex ratio occurs by adulthood; all other comparisons were non-significant (for full results see Table S3).

\section{Illustrating differential mortality patterns on sex ratios trends}

The hypothetical sex ratios resulting from our five mortality scenarios are presented in Figure 3. When comparing the observed sex ratios across Agta juvenile age cohorts (see Figure 1 - we do not map them onto the model populations to avoid conflating period and cohort data) with the hypothetical sex ratios it is apparent that the scenarios based on systematic female neglect (scenario 4) and female infanticide with additional neglect (scenario 2) do not match the trajectory of the Agta sex ratios. The Agta ratios start high and then progressively decrease, best matching the line illustrating a male-biased sex ratio from birth (scenario 5). The female infanticide only (scenario 3) and higher male mortality 'baseline' (scenario 1) ratios also decline across age cohorts; however, the sex ratio of 3.00 for the subset of 'witnessed' births $(n=16)$ points against scenario 3 and the Agta sex ratios do not become female biased (scenario 1). Thus, the patterns derived from these scenarios are supportive of Agta sex ratios being male biased at birth. 

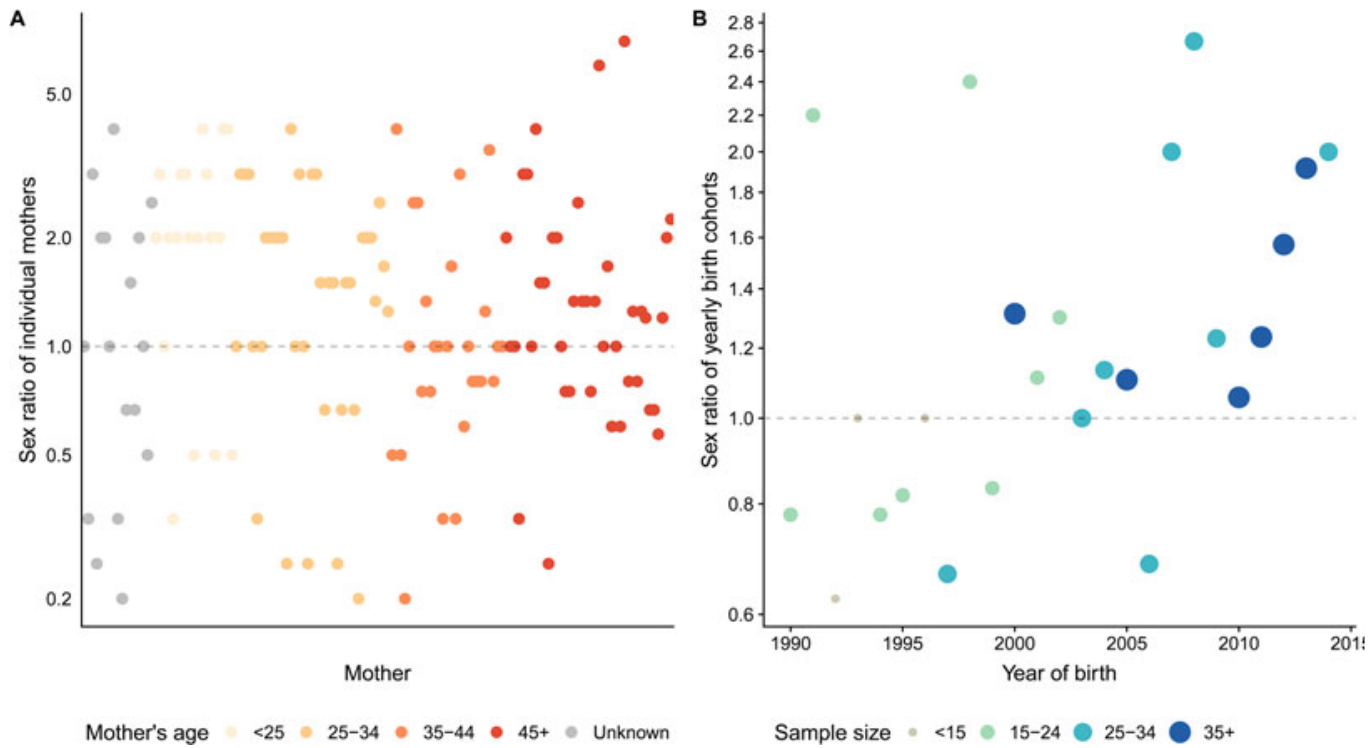

Figure 2. (a) The sex ratio of offspring born to individual mothers - here each dot is a mother, the age of whom is represented in shading. Only mothers with two or more offspring are included. (b) The sex ratio of birth cohorts from 1990 to 2014 . Sample size is indicated by dot size - the larger the dot, the larger the sample. Accuracy is increased from the 2000s onwards as the size of the birth estimates is closer to the expected 35-40 births per year. The dashed line represents a balanced sex ratio. The $y$-axis is log transformed owing to the nature of the distribution of sex ratios.

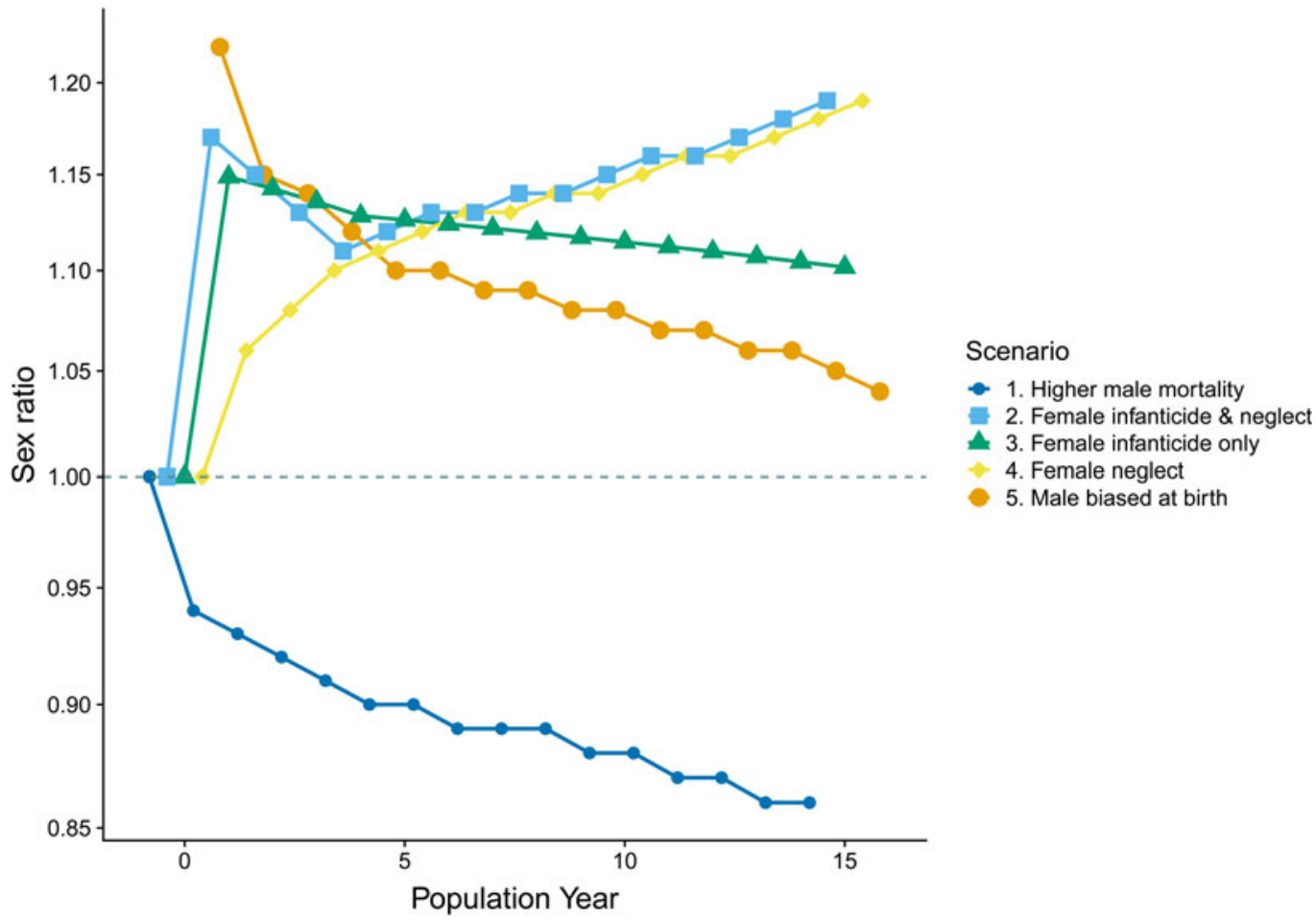

Figure 3. Population sex ratio by age cohort in a hypothetical population under differing sex-specific mortality scenarios. For full details see the Supporting Information. Lines have been dodged to assist viewing when there is significant overlapping. The dashed line represents a balanced (1:1) sex ratio. The $y$-axis is log transformed owing to the nature of the distribution of sex ratios. 
Table 3. The distribution of the deaths of offspring reported by Agta mothers by sex

\begin{tabular}{|c|c|c|c|c|c|c|c|c|c|c|}
\hline \multirow[b]{3}{*}{$\begin{array}{l}\text { Cause of } \\
\text { death }\end{array}$} & \multicolumn{10}{|c|}{ Age cohort } \\
\hline & \multicolumn{3}{|c|}{$<1$ year } & \multicolumn{3}{|c|}{$1-5$ years } & \multicolumn{3}{|c|}{$6-15$ years } & \multirow[b]{2}{*}{$\begin{array}{c}\text { Overall } \\
\text { ratio }\end{array}$} \\
\hline & $\begin{array}{c}\text { Male } \\
n\end{array}$ & $\begin{array}{c}\text { Female } \\
n\end{array}$ & Ratio & $\begin{array}{c}\text { Male } \\
n\end{array}$ & $\begin{array}{c}\text { Female } \\
n\end{array}$ & Ratio & $\begin{array}{c}\text { Male } \\
n\end{array}$ & $\begin{array}{c}\text { Female } \\
n\end{array}$ & Ratio & \\
\hline Disease & 24 & 32 & 0.75 & 22 & 15 & 1.47 & 16 & 14 & 1.14 & 1.02 \\
\hline Non-disease & 6 & 2 & 3.00 & 12 & 3 & 4.00 & 5 & 4 & 1.25 & 2.56 \\
\hline All causes & 30 & 34 & 0.88 & 34 & 18 & 1.89 & 21 & 18 & 1.17 & 1.2 \\
\hline
\end{tabular}

\section{Prediction 2 - females do not receive less parental investment}

Regression analysis indicates that there is no sex bias in the amount of care children receive from their parents when controlling for child age (Tables S4-6, Figure S2). While younger children interact significantly more with parents, the sex of the child has no effect, irrespective of the type of investment (high, low or total investment interactions) or source of investment (both parents combined, mother or father). Additionally, Wilcoxon rank sum tests found no significant differences between the levels of parental investment received by full brothers and sisters (Table S7).

\section{Prediction 3 - mortality is male, not female, biased}

\section{Proportion tests on cause of deaths and gender bias in stillbirths}

While disease-related mortality was equally likely in both sexes, females were less likely to die of nondisease causes than males: Pearson $\chi^{2}$ (d.f. $\left.=1, n=155\right)=4.726, p=0.030$ (Table 3). No difference was found between the proportions of males $(n=13)$ and females $(n=7)$ reported to have been stillborn (males $=0.65$, LCI $=0.44$ one-tailed).

\section{Hazard analysis on juvenile mortality}

In the best fit model, for every month after birth until the age of 16 years (192 months), the hazard of death was $56 \%$ higher for males compared with females [hazard ratio $=1.557, p=0.011,95 \%$ CI $(1.113,2.178)]$, after controlling for offspring's year of birth. Neither offspring's birth order or year of birth was a significant predictor. For full results see Table S8.

\section{Discussion}

The juvenile sex ratio in the Palanan Agta is male biased; however, contrary to what has commonly been assumed, we find no evidence that females experience higher levels of juvenile mortality. The hazard of death across the period of parental investment was not higher for females, and females were not more likely to die from either disease- or non-disease-related causes of death. Our analysis of detailed Agta childcare data further finds no evidence that male offspring received preferential treatment. Further, running counter to the suggestion of female-biased mortality is the finding that Agta sex ratios did not increase across the juvenile period, as would be expected if female deaths outstripped those of males. Taken together, these results are not supportive of excessive female mortality. Rather, our results indicate that, in the Agta, males suffer higher levels of mortality during the juvenile period. Males were consistently just over 0.5 times as likely to die in any given month than females, until the age of 16 years. Furthermore, males were more likely to die from non-disease-related causes of death with a sex-specific mortality ratio of 2.56 .

In line with findings of higher male mortality, sex ratios derived from the Agta census data decline across the juvenile cohorts, reaching equilibrium by the end of parental investment. The observed sex 
ratios in the Agta best mirror the sex ratios predicted by a mechanism entailing either pure female infanticide followed by equal investment in female infants or a biological mechanism acting in utero to bias sex ratios in favour of males at birth - both of which predict that sex ratios will decline after infancy owing to male-biased juvenile mortality. Given that female infanticide reflects an active preference for males, it seems unlikely that it would exist in isolation from continued female neglect. Furthermore, given that we find no evidence of parental preference and no differences in the number of reported stillborns by sex and male-biased juvenile mortality, we consider a behavioural explanation for the observed patterns hard to reconcile. Combined with the tendency for individual mothers to report having more sons than daughters and there being more males in the witnessed births and $<1$ year group, we suggest that it is plausible that the Agta sex ratio at birth, in the recent past at least, is substantially male biased as a result of a biological mechanism adjusting the primary and/ or secondary sex ratio.

Evidence supports a variety of proximate biological mechanisms by which sex ratios may be skewed by birth. For instance, the sex ratio at conception may be influenced paternally, as a result of an excess of sperm carrying X- or Y-bearing chromosomes, which is influenced by the ratio of testosterone to gonadotrophin (for a review see Navara 2013). The majority of the literature, however, focuses on the maternal role in sex manipulation. For instance, the viscosity of cervical mucus may be increased by greater production of estrogen, aiding X-bearing sperm (Navara 2013). More recent work has estimated the sex ratio at conception to be balanced in a subsample of US conceptions, after which differential mortality during gestation determines the sex ratio at birth (Orzack et al. 2015).

After conception, in vitro studies have shown that glucose has a different influence on the development of male and female blastocysts, with higher levels of glucose inhibiting the development of female conceptuses (for a review see Cameron 2004). Stress is associated with higher circulating levels of glucose, thus maternal stress could result in a greater production of male offspring (Cameron 2004), pointing to a means by which extrinsic risk may influence secondary sex ratios. Further, a recent study of gestational mortality and the trajectory of sex ratios across gestation in the US found total female mortality to be higher (Orzack et al. 2015). In support of facultative adjustment, from the expanding blastocyst phase there is sexual dimorphism in interferon-tau expression (Larson et al. 2001), the molecule which signals pregnancy to the mother (Bazer et al. 1997); this may provide plasticity in the selection of embryos (Flint et al. 1997; Larson et al. 2001).

In the case of the Agta, our results are suggestive of a Fisherian mechanism, with an early sex ratio bias towards males countering male-biased juvenile mortality. Male children seem more likely to die from events primarily beyond parental control, in line with the existing literature indicating male offspring to be subject to greater extrinsic mortality risk (Wells 2000). Thus, by producing more males at birth, parents are equalising their investment between the sexes as males are the least costly sex (Fisher 1930). While we did not test whether male offspring are more cooperative than females, and so cannot empirically rule this possibility out, the lack of bias in parental investment points against this explanation. The fact we find sex ratios balanced at the end of parental investment also runs counter to this position - Agta parents, by whatever mechanism, do not manipulate sex ratios such that they have more male offspring by the time they reach their peak productivity, as would be expected if males were the 'most valuable' sex.

Although the evidence presented here best supports a Fisherian explanation, rather than a behavioural mechanism, evolutionary-based explanations for sex ratios are not mutually exclusive (Sieff et al. 1990); individuals within a population experience different conditions and it should not be assumed all individuals will pursue the same strategy. It is a limitation of our study that we must rely on crosssectional cohort data and retrospectively reported reproductive histories that cannot account for longitudinal maternal condition, and so are unable to assess the strategies of individual mothers (West et al. 2002). We expect any biological mechanism that adjusts at-birth sex ratios to be universal in humans, thus all individuals (or most likely, all females) are capable of facultatively producing more offspring of a given sex, where this would benefit their fitness. However, it does not follow that the majority of women in all foraging populations will pursue a strategy of having more males. 
Variations in juvenile mortality risk and/or the relative benefits of having males vs females owing to their productivity, for instance, are expected to lead to variations in the reproductive strategies of individuals within and between populations.

This latter point is illustrated by the differences and similarities between the Agta living in Palanan and Casiguran. In Casiguran Headland (1989) reports a biased juvenile sex ratio during two population censuses (1.22 in 1977 and 1.45 in 1984), and similar to Palanan, owing to male-biased juvenile mortality (Ross et al. 2016), sex ratios decline over time from infancy (1.14 and 1.68 in $0-4$ year olds) to adulthood ( 0.9 and 0.83 in the $>15 \mathrm{~s}$ ). However, in 1977 no cohort was statistically different from 1:1, while in 1984 the juvenile cohorts were skewed and the adult cohort balanced (Headland 1989). Furthermore, retrospective reproductive histories from Casiguran showed skewed sex ratios (0.515); however, the 95\% CI overlapped with $0.5(0.49,0.53)$ (Headland et al. 2011). A variety of social factors potentially underlie these differences. The Agta of Casiguran have experienced relatively more social and economic disruption by loggers, miners and settlers resulting in their becoming peasant labours, with low status and low survival rates (Headland 1988). One consequence of this was the advent of hypergyny, with Agta women marrying 'higher' status non-Agta males to ensure access to farm land (Early and Headland 1998; Ross et al. 2016), a trend which has not been reported in Palanan. When hypergyny occurs, the relative fitness benefits of daughters may be heightened, leading parents to increase investment in female offspring (Bailey 1988; Bereczkei and Dunbar 1997; Cronk 1991; Hewlett 1993), indicated by greater investment (inferred from differential mortality) in first-born daughters compared with first-born sons in Casiguran (Ross et al. 2016). Consequently, the Agta in Casiguran may be facing opposing forces - increased male mortality making sons 'cheaper' vs hypergyny making daughters more advantageous - leading to a divergence from patterns observed in Palanan.

Given our small sample size, we do not wish to emphasise that the Palanan Agta are 'special' or overemphasise the definitiveness of our results. Future comparative studies with significantly more statistical power and robust design should further explore the relationship between sex ratios at birth and sex-specific mortality patterns. Nonetheless, while the Agta are a small population, the male bias in infancy was significantly higher than the global male bias [itself suggested to be compensating for higher male mortality (Fisher 1930; Mace and Jordan 2005)], which is unsurprising given the high extrinsic risks facing Agta boys. Therefore, this case study offers support to an adaptive hypothesis and acts as the first step in stimulating future research.

By taking a multifaceted approach, we hope to have provided sufficient cause for looking more critically at behavioural-based assumptions regarding male-biased sex ratios in foraging populations and, in the absence of evidence, avoid the further invocation of gendercide. A priori assumptions of female infanticide and/or neglect not only unnecessarily stigmatise groups, but also mean that interventions aimed at improving child outcomes are potentially misdirected (Shenk et al. 2014). Thus, we emphasise the cautionary point that, without exploring, in detail, mortality trends and parental investment strategies in a given population, it is impossible to comment on the behavioural or biological mechanisms behind sex ratio trends.

The Palanan Agta display male-biased sex ratios; however, we find no evidence of biased parental investment or higher female mortality - in fact mortality risk is male biased, as a result of an excess of non-disease related deaths. Sex ratios decline across age cohorts, becoming balanced by the end of parental investment, further indicating that male juveniles die at higher rates and suggesting that Agta mothers are responding, in accordance with the predictions of Fisher (1930), by adaptively adjusting their sex ratios at birth to equalise parental investment across the sexes. Thus, the Agta appear provide evidence to in support of adaptive manipulation of sex ratios, without recourse to active, or passive, gendercide.

Supplementary material. The supplementary material for this article can be found at https://doi.org/10.1017/ehs.2019.4

Author ORCIDs. (D) Abigail E. Page, 0000-0002-0973-1569

Acknowledgements. We would like to thank our research assistants in the Philippines and the Agta for their time and patience, as well as Daniel Smith and Sylvain Viguier for their work in data collection. We are also grateful to Lee Cronk 
and a second anonymous reviewer for their wholehearted and productive engagement in the review process, which undoubtedly improved the paper, as well as Rebecca Sear and the Evolutionary Demography Research Group at the London School of Hygiene and Tropical Medicine for their helpful comments on an earlier version of the manuscript. This project was funded by Leverhulme Trust Grant RP2011-R 045 to A.B.M. and a MRC and DIFD Fellowship MR/P014216/1 to A.E.P.

Author contributions. A.E.P. and S.M. designed and developed the study. A.B.M. led the research project and provided guidance. A.E.P. and S.M. conducted analysis and wrote the first draft. A.E.P., M.D. and A.B.M. conducted data collection. All authors contributed to paper revisions.

Competing interests. The authors declare that they have no competing interests.

Data availability. The authors declare that the data and code supporting the findings of this study are available and can be found at the OSF project site: https://osf.io/72umn/

\section{References}

Austad SN and Fischer KE (2016) Sex differences in lifespan. Cell Metabolism 23(6), 1022-1033; https://oi.org/10.1016/j. cmet.2016.05.019

Bailey RC (1988) The significance of hypergyny for understanding subsistence behavior among contemporary hunters and gatherers. In BV Kennedy and GM LeMoine (eds), Diet and Subsistence: Current Archaeological Perspectives (pp. 57-65). Calgary: University of Calgary.

Balikci A (1970) The Netsilik. Garden City: The Natural History Press.

Bazer FW, Spencer TE and Ott TL (1997) Interferon tau: A novel pregnancy recognition signal. American Journal of Reproductive Immunology 37, 412-420.

Beckerman S, Lizarralde M, Peluso D, Yvinec C, Harris N, Parker D, Walker R and Hill K (2017) Partible paternity, the secondary sex ratio, and a possible Trivers-Willard effect. Current Anthropology 58(4), 540-543; https://doi.org/10.1086/ 692984

Bereczkei T and Dunbar RIM (1997) Female-biased reproductive strategies in a Hungarian Gypsy population. Proceedings of the Royal Society B: Biological Sciences 264, 17-22.

Blurton Jones NG (2016) Demography and Evolutionary Ecology of Hadza Hunter-Gatherers. Cambridge: Cambridge University Press.

Cameron EZ (2004) Facultative adjustment of mammalian sex ratios in support of the Trivers - Willard hypothesis: evidence for a mechanism. Proceedings of the Royal Society B: Biological Sciences, 271, 1723-1728; https://doi.org/10.1098/rspb.2004. 2773

Catalano R, Yorifuji T and Kawachi I (2013) Natural selection in utero: evidence from the Great East Japan Earthquake. American Journal of Human Biology: The Official Journal of the Human Biology Council 25(4), 555-559; https://doi. org/10.1002/ajhb.22414

CIA (2018) World Factbook.

Clutton-Brock TH and Iason GR (1986) Sex ratio variation in mammals. The Quarterly Review of Biology 61(3), 339-374; https://doi.org/10.1086/415033

Clutton-Brock TH, Guinness FE and Albon SD (1982) Red Deer: the Behaviour and Ecology of two Sexes. Chicago, IL: University of Chicago Press.

Crittenden AN and Marlowe FW (2008) Allomaternal care among the Hadza of Tanzania. Human Nature 19(July), 249262; https://doi.org/10.1007/s12110-008-9043-3

Cronk L (1991) Preferential parental investment in daughters over sons. Human Nature 2(4), 387-417; https://doi.org/10. 1007/BF02692198

Cronk L (2007) Boy or girl: gender preferences from a Darwinian point of view. Reproductive BioMedicine Online; https://doi. org/10.1016/S1472-6483(10)60546-9

Diekmann Y, Smith D, Gerbault P, Dyble M, Page AE, Chaudhary N, Bamberg Migliano A and Thomas MG (2017) Accurate age estimation in small-scale societies. Proceedings of the National Academy of Sciences, 1619583114; https:// doi.org/10.1073/pnas.1619583114

Drevenstedt G, Crimmins E, Vasunilashorn S and Finch C (2008) The rise and fall of excess male infant mortality. Proceedings of the National Academy of Sciences of the United States of America 105(13), 5016-5021; https://doi.org/10. 1073/pnas.0800221105

Dyble M, Salali GD, Chaudhary N, Page A, Smith D, Thompson J, Vinicius L, Mace R and Migliano AB (2015) Sex equality can explain the unique social structure of hunter-gatherer bands. Science 348(6236), 796-798; https://doi.org/ 10.1126/science.aaa5139

Dyble M, Thompson J, Smith D, Salali GD, Chaudhary N, Page AE, Vinicuis L, Mace R and Migliano AB (2016) Networks of food sharing reveal the functional significance of multilevel sociality in two hunter-gatherer groups. Current Biology 26, 2017-2021; https://doi.org/10.1016/j.cub.2016.05.064 
Early JD and Headland TN (1998) Population Dynamics of a Philippine Rain Forest People: The San Ildefonso Agta. Gainesville, FL: University Press of Florida.

Eder JF (1987) On the Road to Tribal Extinction: Depopulation, Deculturation, and Maladaptation among the Batak of the Philippines. Berkeley, CA: University of California Press.

Ellison GT, de Wet T, Matshidze KP and Cooper P (2000) The reliability and validity of self-reported reproductive history and obstetric morbidity amongst Birth to Ten mothers in Soweto. Curationis 23(4), 76-80.

Emlen ST, Merritt Emlen J and Levin SA (1986) Sex-ratio selection in species with helpers-at-the-nest. The American Naturalist 127, 1-8; https://doi.org/10.1086/284463

Fisher RA (1930) The Genetical Theory of Natural Selection. Oxford: Clarendon Press.

Flint APF, Albon SD and Jafar SI (1997) Blastocyst development and conceptus sex selection in red deer Cervus elaphus: studies of a free-living population on the Isle of Rum. General and Comparative Endocrinology 383, 374-383.

Gardner PM (1988) The paliyans. In MG Bicchieri (ed.), Hunters and Gatherers Today (pp. 404-450). Prospect Heights: Waveland Press.

Gellatly C and Petrie M (2017) Prenatal sex selection and female infant mortality are more common in India after first-born and second-born daughters. Journal of Epidemiology and Community Health 71(3), 269-274; https://doi.org/10.1136/jech2016-207489

Gurven M and Kaplan H (2007) Longevity among hunter-gatherers: a cross-cultural examination. Population and Development Review 33(June), 321-365.

Hamilton WD (1967) Extraordinary sex ratios. Science 156(3774), 477-488; https://doi.org/10.1126/science.156.3774.477

Headland TN (1988) Ecosystemic change in a Philippine tropical rainforest and its effects on a Negrito foraging society. Tropical Ecology 29, 121-135.

Headland TN (1989) Population decline in a Philippine Negrito hunter-gatherer society. American Journal of Human Biology 1(1), 59-72.

Headland TN, Headland JD and Uehara RT (2011) Agta Demographic Database: Chronicle of a Hunter-Gatherer Community in Transition. SIL Language and Culture Documentation and Description 2; https://www.sil.org/resources/ publications/entry/9299

Hesketh T and Xing ZW (2006) Abnormal sex ratios in human populations: causes and consequences. Proceedings of the National Academy of Sciences 103(36), 13271-13275; https://doi.org/10.1073/pnas.0602203103

Hewlett BS (1991) Demography and Childcare in preindustrial societies. Journal of Anthropological Research 42(1), $1-37$.

Hewlett BS (1993) Intimate Fathers: the Nature and Context of Aka Pygmy Paternal Infant Care. Ann Arbor, MI: University of Michigan Press.

Hewlett BS, Lamb ME, Leyendecker B and Schölmerich A (2000) Parental investment strategies among Aka foragers, Ngandu farmers and Euro-American urban-industrialists. In Adaptation and Human Behaviour: an Anthropological Perspective (pp. 155-177). New York: Aldine de Gruyter.

Hill K and Hurtado AM (1996) Aché Life History: The Ecology and Demography of a Foraging People. New Haven, CT: Aldine de Gruyter; https://doi.org/10.1016/S1090-5138(97)00035-4

Hill KR and Kaplan HS (1988) Tradeoffs in male and female reproductive strategies among the Ache, part 1. In L Betzig, P Turke and M Borgerhoff Mulder (eds), Human Reproductive Behavior (pp. 277-290). Cambridge: Cambridge University Press.

Hill K, Hurtado AM and Walker RS (2007) High adult mortality among Hiwi hunter-gatherers: implications for human evolution. Journal of Human Evolution 52, 443-454; https://doi.org/10.1016/j.jhevol.2006.11.003

Hurtado AM and Hill KR (1987) Early dry season subsistence ecology of Cuiva (Hiwi) foragers of Venezuela. Human Ecology 15(2), 163-187; https://doi.org/10.1007/BF00888379

Irwin C (1989) Lords of the Arctic: wards of the state. The growing Inuit population. Northern Perspectives 17(1), 2-12.

James WH (1986) Hormonal control of sex ratio. Journal of Theoretical Biology 118(4), 427-441; https://doi.org/10.1016/ S0022-5193(86)80163-1

Kelly RL (2013) The Lifeways of Hunter-Gatherers: The Foraging Specturm (2nd edn) Cambridge: Cambridge University Press.

Komdeur J, Daan S, Tinbergen J and Mateman C (1997) Extreme adaptive modification in sex ratio of the Seychelles warbler's eggs. Nature 385(6616), 522-525; https://doi.org/10.1038/385522a0

Kramer KL (2010) Cooperative breeding and its significance to the demographic success of humans. Annual Review of Anthropology 39(1), 417-436; https://doi.org/10.1146/annurev.anthro.012809.105054

Labov JB, William Huck U, Vaswani P and Lisk RD (1986) Sex ratio manipulation and decreased growth of male offspring of undernourished golden hamsters (Mesocricetus auratus). Behavioral Ecology and Sociobiology 18(4), 241-249; https:// doi.org/10.1007/BF00300000

Larson MA, Kimura K, Kubisch HM and Roberts RM (2001) Sexual dimorphism among bovine embryos in their ability to make the transition to expanded blastocyst and in the expression of the signaling molecule IFN-t. Proceedings of the National Academy of Sciences of the United States of America 98(17), 9677-9682. 
Lazarus J (2002) Human sex ratios: adaptations and mechanisms, problems and prospects. In ICW Hardy (ed.), Sex Ratios: Concepts and Research Methods (pp. 287-311). Cambridge: Cambridge University Press; https://doi.org/10.1017/ CBO9780511542053.015AQ7

Mace R and Jordan F (2005) The evolution of human sex ratio at birth: a bio-cultural analysis. In R Mace, C Holden and S Shennan (eds), The Evolution of Cultural Diversity: a Phylogenetic Approach (pp. 207-216). London: UCL Press.

Maynard Smith J (1980) A new theory of sexual investment. Behavioral Ecology and Sociobiology 7(3), 247-251; https://doi. org/10.1007/BF00299371

McClure PA (1981) Sex-biased litter reduction in food-restricted wood rats (Neotoma floridana). Science, 211(4486), 10581060; https://doi.org/10.1126/science.211.4486.1058

McElreath R and Boyd R (2007) Mathematical Models of Social Evolution: a Guide for the Perplexed. London: University of Chicago Press.

Meehan CL (2005) The effects of residential locality on parental and alloparental investment among the Aka foragers of the central African Republic. Human Nature 16(1), 58-80; https://doi.org/10.1007/s12110-005-1007-2

Minter T (2010) The Agta of the Northern Sierra Madre: Livelihood Strategies and Resilience Among Philippine HunterGatherers. Leiden: Leiden University.

Morris B (1982) Economy, affinity and inter-cultural pressure: notes around hill Pandaram group structure. Man 17(3), 452-461.

Navara KJ (2013) Hormone-mediated adjustment of sex ratio in vertebrates. Integrative and Comparative Biology 53(6), 877887. https://doi.org/10.1093/icb/ict081

Orzack HS, Stubblefield JW, Akmaev VR, Colls P, Munné S, Scholl T, Steinsaltz D and Zuckerman JE (2015) The human sex ratio from conception to birth. Proceedings of the National Academy of Sciences of the United States of America 112 (16), E2102-E2111; https://doi.org/10.1073/pnas.1416546112

Page AE (2016) On Trade offs and Communal Breeding: the Behavioural Ecology of Agta Foragers. London: University College London.

Page AE, Viguier S, Dyble M, Smith D, Chaudhary N, Salali GD, Thompson J, Vinicius L, Mace R and Migliano AB (2016) Reproductive trade-offs in extant hunter-gatherers suggest adaptive mechanism for the Neolithic expansion. Proceedings of the National Academy of Sciences of the United States of America 113(17), 4694-4699. https://doi.org/10. 1073/pnas.1524031113

Peterson JT (1978) The Ecology of Social Boundaries: Agta Foragers of the Philippines. London: University of Illinois Press.

Promislow DEL (1992) Costs of sexual selection in natural populations of mammals. Proceedings of the Royal Society B: Biological Sciences 247(1320), 203-210. https://doi.org/10.1098/rspb.1992.0030

Rasmussen K (1931) The Netsilik Eskimos, ed. NF Gyldeddalske Boghandel. Copenhagen.

R Core Team (2012) R: a Language and Environment for Statistical Computing. Vienna: R Foundation for Statistical Computing; http://www.r-project.org/

Reza A, Mercy JA and Krug E (2001) Epidemiology of violent deaths in the world. Injury Prevention 7(2), 104-111; https:// doi.org/10.1136/ip.7.2.104

Rose FGG (1960) Clasification of Kin, Age Structure and Marriage Amongst the Groote Eylandt Aboriginies. Berlin: Akademie-Verlag.

Ross CT, Borgerhoff M, Winterhalder B, Uehara R, Headland J and Headland T (2016) Evidence for quantity-quality trade-offs, sex-specific parental investment, and variance compensation in colonized Agta foragers undergoing demographic transition. Evolution and Human Behavior 37(5), 350-365; https://doi.org/10.1016/j.evolhumbehav.2016.02.005

Sharp RL (1940) An Australian Aboriginal population. Human Biology 12(4), 481-507.

Shenk MK, Towner MC, Starkweather K, Atkisson CJ and Alam N (2014) The evolutionary demography of sex ratios in rural Bangladesh. In MA Gibson and D Lawson (eds), Applied Evolutionary Anthropology: Darwinian Approaches to Contemporary World Issues (pp. 141-173). London: Springer.

Sieff DF, Betzig L, Cronk L, Fix AG, Flinn M, Sattenspiel L, Gibson K, Ann Herring D, Howell N, Johansson SR, Pavlík Z, Sheets JW, Smith EA, Voland E and Siegelkow E (1990) Explaining biased sex ratios in human populations: a critique of recent studies. [And Comments and Reply.] Current Anthropology 31(1), 25-48; https://doi.org/10.1086/ 203801

Silk JB (1983) Local resource competition and facultative adjustment of sex ratios in relation to competitive abilities. The American Naturalist 121(1), 56-66; https://doi.org/10.1086/284039

Skogland T (1986) Sex ratio variation in relation to maternal condition and parental investment in wild reindeer. Oikos 46, 417-419.

Smith EA and Smith SA (1994) Inuit sex-ratio variation. Current Anthropology 35(5), 595-614.

Trivers RL and Willard DE (1973) Natural selection of parental ability to vary the sex ratio of offspring. Science; https://doi. org/10.1126/science.179.4068.90

Turnball C (1961) The Forest People. London: Bodley Head.

Uggla C and Mace R (2016) Parental investment in child health in sub-Saharan Africa: a cross-national study of healthseeking behaviour. Royal Society Open Science 3(2), 150460; https://doi.org/10.1098/rsos.150460

United Nations (2017) World Population Prospects 2017; https://esa.un.org/unpd/wpp/ 
Watts C and Zimmerman C (2002) Violence against women: global scope and magnitude. Lancet; https://doi.org/10.1016/ S0140-6736(02)08221-1

Wells JCK (2000) Natural selection and sex differences in morbidity and mortality in early life. Journal of Theoretical Biology 202(1), 65-76; https://doi.org/10.1006/jtbi.1999.1044

West S, Reece SE and Sheldon BC (2002) Sex ratios. Heredity 88, 117-124; https://doi.org/10.1016/B978-0-12-374984-0. 01406-6

Weyer EM (1932) The Eskimos: their Environment and Folkways. New Haven, CT: Yale University Press.

Yengoyan AA (1970) Demographic factors in Pitjandjara social organisation. In RM Berndt (ed.), Australian Aboriginal Anthropology (pp. 70-91). Nedlands: University of Western Australia.

Cite this article: Page AE, Myers S, Dyble M, Migliano AB (2019). Why so many Agta boys? Explaining 'extreme' sex ratios in Philippine foragers. Evolutionary Human Sciences 1, e5, 1-17. https://doi.org/10.1017/ehs.2019.4 